\title{
Results of adjuvant radiation therapy for locoregional perihilar cholangiocarcinoma after curative intent resection
}

This article was published in the following Dove Press journal:

OncoTargets and Therapy

21 April 2017

Number of times this article has been viewed

\author{
Kai-Ming Leng ${ }^{1, *}$ \\ Yue-Ping Liu',* \\ Zhi-Dong Wang' \\ Xiang-Yu Zhong' \\ Guan-Qun Liao ${ }^{2}$ \\ Peng-Cheng Kang' \\ Yun-Fu Cui' \\ Xing-Ming Jiang' \\ 'Department of Hepatopan- \\ creatobiliary Surgery, Second Affiliated \\ Hospital of Harbin Medical University, \\ Harbin, ${ }^{2}$ Department of General \\ Surgery, Foshan Hospital Affiliated to \\ Southern Medical University, Foshan, \\ People's Republic of China \\ *These authors contributed equally \\ to this work
}

Purpose: This study sought to define the role of adjuvant radiation therapy (RT) for patients with curative intent resection of perihilar cholangiocarcinoma (pCCA).

Patients and methods: By using the Surveillance, Epidemiology and End Results (SEER) registry, 1,917 patients with non-metastatic pCCA who underwent surgical resection from 1988 to 2009 were included in this study. Propensity score methods were used to compare the survival outcomes of patients treated with and without adjuvant RT after controlling for selection bias. Results: Of the 1,917 patients, 762 (39.7\%) received adjuvant RT. In the unmatched population, median overall survival (OS) for patients receiving adjuvant RT compared with those undergoing surgery alone was 23 versus 22 months $(P=0.651)$. Patients who received adjuvant RT were younger (65 vs 68 years, $P<0.001$ ), had more regional diseases $(86.0 \%$ vs $76.7 \%$, $P<0.001)$, and had more positive lymph nodes $(43.8 \%$ vs $32.2 \%, P<0.001)$. In the matched population, adjuvant RT did not show better OS (22 vs 23 months, $P=0.978$ ) or cancer-specific survival (CSS) (17 vs 18 months, $P=0.554$ ).

Conclusion: Adjuvant RT is not associated with improved survival of patients with resected pCCA. These data suggest that adjuvant RT should not be routinely used to treat patients with pCCA outside research trials. Ideally, prospective randomized trials should be performed to verify the conclusion of this study.

Keywords: perihilar cholangiocarcinoma, radiation therapy, SEER, propensity score, survival, surgery

\section{Introduction}

Cholangiocarcinoma (CCA) is an uncommon tumor that constitutes $<2 \%$ of all human malignancies. ${ }^{1}$ Perihilar cholangiocarcinoma (pCCA) is a subtype of CCA that locates at the area between the insertion of the cystic duct into the common bile duct and the second-degree bile ducts. It accounts for approximately two-thirds of all CCAs. $^{2,3}$ pCCA possesses a peculiar growth behavior that spreads longitudinally and frequently invades major vascular structures. It is a relatively slow-growing cancer and is usually small at clinical presentation. Therefore, it is usually too advanced for radical surgery after being diagnosed. This makes pCCA a devastating cancer with a median survival of $<1$ year if untreated.

Complete resection is recognized as an effective therapy for pCCA. It is found that 5-year survival and median survival among patients with a complete resection range from $27 \%$ to $45 \%$ and from 27 to 58 months, respectively. ${ }^{4-7}$ Prognosis of pCCA is still poor despite great improvement. Moreover, locoregional recurrence is found in $\sim 60 \%$ of patients undergoing curative resection for $\mathrm{pCCA}$, whereas distant
Correspondence: Yun-Fu Cui; Xing-Ming Jiang Department of Hepatopancreatobiliary Surgery, Second Affiliated Hospital of Harbin Medical University, No 246, Xuefu Street, Nangang District, Harbin 150086, People's Republic of China

$\mathrm{Tel}+8645 \mathrm{I} 86605 \mathrm{II} 3$

Fax +86 45I 8660 5II3

Email yfcui777@I63.com; xmjiang@hrbmu.edu.cn 
metastases are seen in almost $40 \%$ of cases. ${ }^{8}$ As such, radiotherapy has been proposed and, to a varying degree, is used currently as adjuvant therapy for resected pCCA. However, it remains controversial. ${ }^{9-16}$ Several research studies have shown an improved survival benefit with adjuvant radiation therapy (RT) among patients undergoing curative intent operations..$^{9,13-15,17}$ By contrast, some other studies did not detect a survival benefit from adjuvant RT. ${ }^{10,12}$ It is possible that the debate is largely attributed to the overrepresentation of pCCA patients with adverse tumor characteristics in the cohorts that received adjuvant RT. It is reported that patients with positive resection margin, lymph node (LN) metastasis, and high histological grade were more likely to receive adjuvant $\mathrm{RT} .^{12,13,15}$ The selection bias in the receipt of adjuvant RT might result in inaccurate interpretation of the efficacy of adjuvant RT.

This study used the Surveillance, Epidemiology and End Results (SEER) database to evaluate the effect of adjuvant RT on the survival outcome of radically resected pCCAs. In order to minimize the selection bias in patients received adjuvant RT, propensity score matching was applied. The present study could provide the basis for the optimal therapeutic approach to pCCA.

\section{Patients and methods}

The SEER database represent $28 \%$ of the US population, and the 18 registries participating in the SEER program capture $\sim 97 \%$ of incident cancers. ${ }^{18,19}$ The SEER database data are publicly available. Use of the SEER database data does not require informed consent, and this study was approved by the ethics committee of the Second Affiliated Hospital of Harbin Medical University and Foshan Hospital Affiliated to Southern Medical University.

Several predefined variables were used to screen eligible patients: "CS SCHEMA v0204+" of "008-Bile Ducts Perihilar," "Age at diagnosis" of $\geq 20$, and "Year of diagnosis" ranging from 1988 to 2009. The International Classification of Diseases for Oncology, 3rd Edition (ICD-0-3) codes were used to identify cases of pCCA. pCCA was defined as tumors with histological codes of 8010,8020 , $8040,8070,8041,8140,8144,8160,8161,8162,8163,8260$, $8310,8480,8490$, and 8560 with a topographic code of C24.0 and C22.1. Patients without microscopic diagnostic confirmation, unknown diagnostic confirmation, or diagnosed on autopsy were excluded. Patients were also excluded if they survived $<2$ months, had unknown radiotherapy information, presented with distant metastasis, or with a surgery code not consistent with surgical resection. Figure 1 depicts a flowchart regarding patient selection for the study cohort.
Briefly, the cohort included all patients aged $\geq 20$ years who had a histological diagnosis of pCCA who underwent curative intent surgical resection with known disease stage and radiation status between 1988 and 2009.

Data collected for each patient included patient demographics (age at diagnosis, race/ethnicity, gender, year of diagnosis, and marital status), tumor characteristics (tumor size, grade, and tumor stage), and treatment modality (sequence of radiation and status of adjuvant RT). Tumor stage was reported for only years 2004 and later. For patients from 1988 to 2003, tumor stage was derived from the extent of the primary tumor. To facilitate the current analysis, tumor stage was classified into two categories: localized disease (stages T1-T2) and regional disease (stages T3-T4 and/or node positive). According to the SEER classification of surgery, radical resection was defined as partial or total removal of primary site plus partial or total removal of other organs. Limited resection was defined as either partial or total operative removal of only the primary site.

\section{Propensity score matching}

Because of the nonrandom distribution in the receipt of adjuvant RT, the survival outcomes could be influenced by the selection bias. A propensity score is defined as the probability of being assigned to adjuvant RT group or surgeryalone group based on the clinicopathologic characteristics. ${ }^{20}$ Propensity score matching using the greedy matching algorithm was used to compare the survival outcomes of patients treated with and without adjuvant RT after controlling for selection bias. In the calculation of the propensity scores, a nonparsimonious logistic regression model with the treatment of interest (adjuvant RT) as the outcome measure was used considering predefined baseline covariates, including year of diagnosis, gender, age at diagnosis, race, tumor extent, LN status, tumor size, and extent of surgery. ${ }^{21}$ In the matched population, univariate and multivariate analyses for prognostic factors were conducted.

\section{Statistical analysis}

Overall survival (OS) and cancer-specific survival (CSS) were the primary and secondary outcomes of interest, respectively. OS was calculated from the date of diagnosis to the date of death of any cause. CSS was defined as the time of diagnosis until pCCA-related death. The chi-square test was used to compare the clinical and demographic factors between patients grouped by categorical variables. Survival outcomes before and after propensity score matching were conducted using the Kaplan-Meier method and compared using the log-rank test. The Cox proportional hazard model 


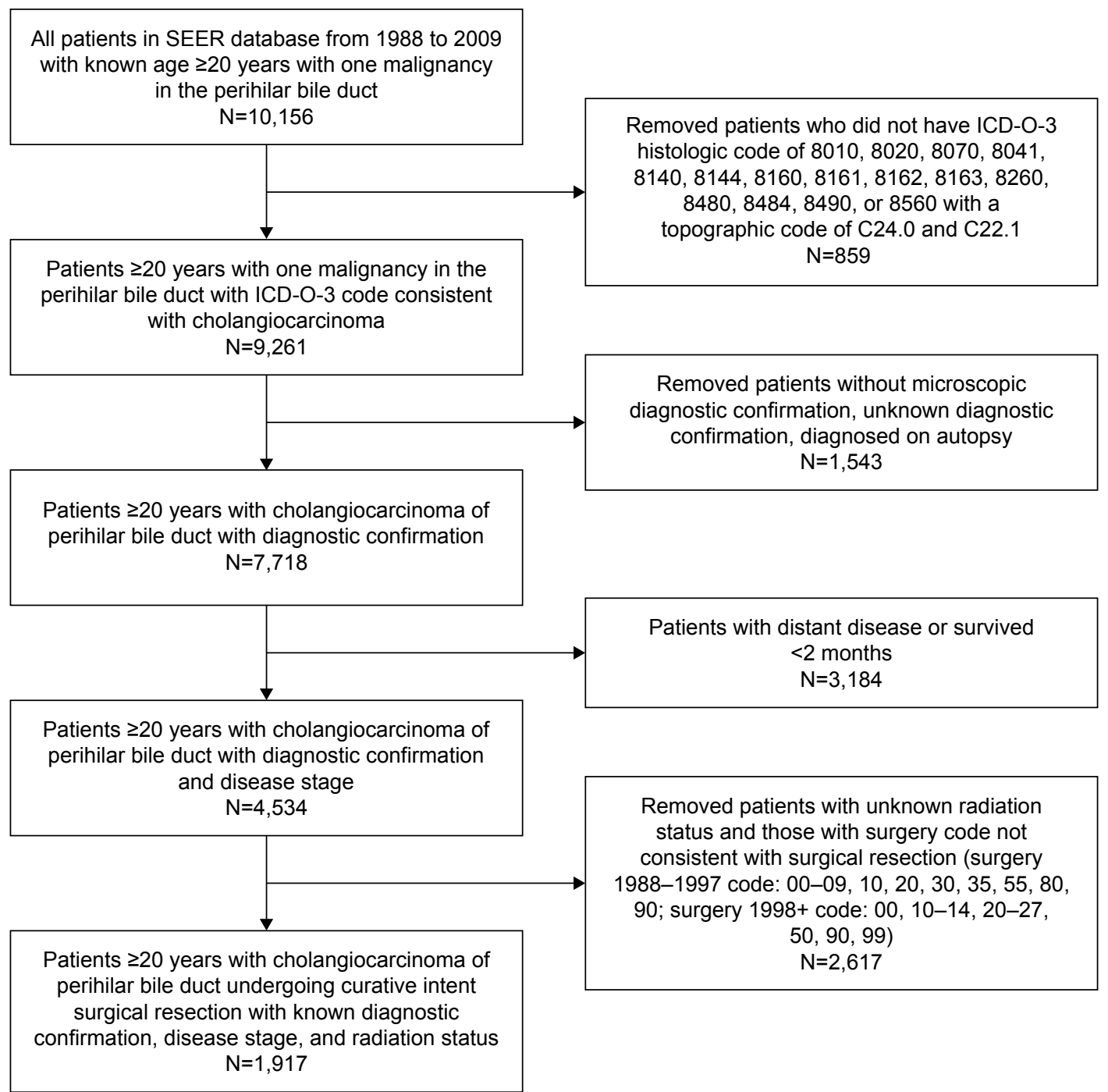

Figure I Patient selection flowchart.

Abbreviations: ICD-O-3, International Classification of Diseases for Oncology, 3rd Edition; SEER, Surveillance, Epidemiology and End Results.

was used for multivariate analyses. Clinicopathologic variables with $P$-values $<0.1$ in the univariate analyses were adjusted. $P<0.05$ was considered to be statistically significant in all analyses. Statistical analyses were performed by using SPSS 22.0 (IBM, Armonk, NY, USA) and R version 2.13.0 (R Foundation for Statistical Computing, Vienna, Austria).

\section{Results}

\section{Patient characteristics}

Between 1988 and 2009, 1,917 patients underwent resection for pCCA and met inclusion criteria; 762 (39.7\%) patients received adjuvant $\mathrm{RT}$. The median age of the entire cohort was 67 years (interquartile range $58-74$ years). Most patients were male $(\mathrm{n}=1,157 ; 60.4 \%)$ and white $(\mathrm{n}=1,513 ; 78.9 \%)$. The clinicopathologic characteristics between the two groups are presented in Table 1. Patients receiving adjuvant RT versus surgery alone were younger ( 65 vs 68 years, $P<0.001$ ), had more advanced tumor stage ( $86.0 \%$ vs $76.7 \%, P<0.001)$, and had more positive LN ( $43.8 \%$ vs $32.2 \%, P<0.001)$.

\section{Survival outcomes before propensity score matching}

In the unmatched population $(\mathrm{n}=1,917), 1,642$ patients died at the end of follow-up. The unadjusted median survival was 23 months, and 5 -year rate of OS was $24.5 \%$. There were 1,162 pCCA-related death events, and the median and 5-year rates of CSS were 17 months and 7.7\%, respectively. Kaplan-Meier curves of OS and CSS before propensity score matching are presented in Figure 2. In both OS and CSS, there were no significant differences between the adjuvant RT $(n=762)$ and surgery alone $(n=1,155)$ groups. Median OS for patients receiving adjuvant RT compared with 
Table I Demographics of patients with pCCA between treatment cohorts before and after propensity score matching

\begin{tabular}{|c|c|c|c|c|c|c|}
\hline \multirow[t]{2}{*}{ Variables } & \multicolumn{3}{|c|}{ Before propensity score matching } & \multicolumn{3}{|c|}{ After propensity score matching } \\
\hline & $\begin{array}{l}\text { Adjuvant } \\
\text { RT }(n=762)\end{array}$ & $\begin{array}{l}\text { Surgery alone } \\
(n=I, 155)\end{array}$ & $P$-value & $\begin{array}{l}\text { Adjuvant } \\
\text { RT }(n=65 I)\end{array}$ & $\begin{array}{l}\text { Surgery } \\
\text { alone }(n=65 I)\end{array}$ & $P$-value \\
\hline Age (years) & & & $<0.001$ & & & 0.585 \\
\hline$\leq 49$ & 92 & 94 & & 64 & 55 & \\
\hline $50-59$ & 170 & 173 & & 148 & 130 & \\
\hline $60-69$ & 239 & 369 & & 216 & 236 & \\
\hline $70-79$ & 212 & 375 & & 184 & 190 & \\
\hline $80+$ & 49 & 144 & & 39 & 40 & \\
\hline Gender & & & 0.044 & & & 1 \\
\hline Men & 481 & 676 & & 411 & 411 & \\
\hline Women & 281 & 479 & & 240 & 240 & \\
\hline Race & & & 0.184 & & & 1 \\
\hline White & 595 & 918 & & 537 & 537 & \\
\hline Black & 44 & 81 & & 27 & 27 & \\
\hline Others & 123 & 156 & & 87 & 87 & \\
\hline Year of diagnosis & & & 0.361 & & & 0.287 \\
\hline $1988-1993$ & 91 & 152 & & 86 & 74 & \\
\hline $1994-1999$ & 139 & 203 & & 106 & 122 & \\
\hline $2000-2004$ & 257 & 351 & & 197 & 215 & \\
\hline $2005-2009$ & 275 & 449 & & 262 & 240 & \\
\hline Tumor grade & & & 0.639 & & & I \\
\hline Well or moderate & 458 & 718 & & 406 & 406 & \\
\hline Poor or undifferentiated & 226 & 321 & & 191 & 191 & \\
\hline Unknown & 78 & 116 & & 54 & 54 & \\
\hline LN status & & & $<0.001$ & & & I \\
\hline Negative & 389 & 724 & & 347 & 347 & \\
\hline Positive & 334 & 372 & & 286 & 286 & \\
\hline Unknown & 39 & 59 & & 18 & 18 & \\
\hline Tumor size (mm) & & & 0.176 & & & 0.339 \\
\hline$\leq 20$ & 263 & 447 & & 255 & 230 & \\
\hline$>20$ & 255 & 359 & & 204 & 212 & \\
\hline Unknown & 244 & 349 & & 192 & 209 & \\
\hline Tumor stage & & & $<0.001$ & & & I \\
\hline Localized (TI-T2) & 100 & 255 & & 83 & 83 & \\
\hline $\begin{array}{l}\text { Regional (T3-T4 and/or } \\
\text { node positive) }\end{array}$ & 655 & 886 & & 567 & 567 & \\
\hline Unknown & 7 & 14 & & I & I & \\
\hline Extent of surgery & & & 0.804 & & & I \\
\hline Radical & 402 & 616 & & 355 & 355 & \\
\hline Limited & 360 & 539 & & 296 & 296 & \\
\hline
\end{tabular}

Abbreviations: LN, lymph node; pCCA, perihilar cholangiocarcinoma; RT, radiation therapy.

those undergoing surgery alone was 23 versus 22 months $(P=0.651)$. The median CSS rates of the adjuvant RT and surgery-alone groups were both 17 months $(P=0.853)$.

\section{Prognostic effect of adjuvant RT after propensity score matching}

The propensity score matching was able to create a balanced population including adjuvant RT group $(n=651)$ and surgeryalone group $(n=651)$. Table 1 lists the details of the balance before and after propensity score matching, noting that the potential selection bias in the receipt of adjuvant RT was minimized.
Kaplan-Meier curves of OS and CSS after propensity score matching are presented in Figure 3. The median and 5-year rates of OS for the adjuvant RT and surgery-alone groups were 22 months and $24.2 \%$ and 23 months and $24.6 \%$, respectively. The median and 5-year rates of CSS for the adjuvant RT and surgery-alone groups were 17 months and $8.4 \%$ and 18 months and $9.4 \%$, respectively.

Table 2 shows the results of the univariate analyses for OS and CSS. Age $(P<0.001)$, tumor stage $(P<0.001)$, LN status $(P<0.001)$, tumor grade $(P=0.005)$, and tumor size $(P<0.001)$ were associated factors of OS. For CSS, year 

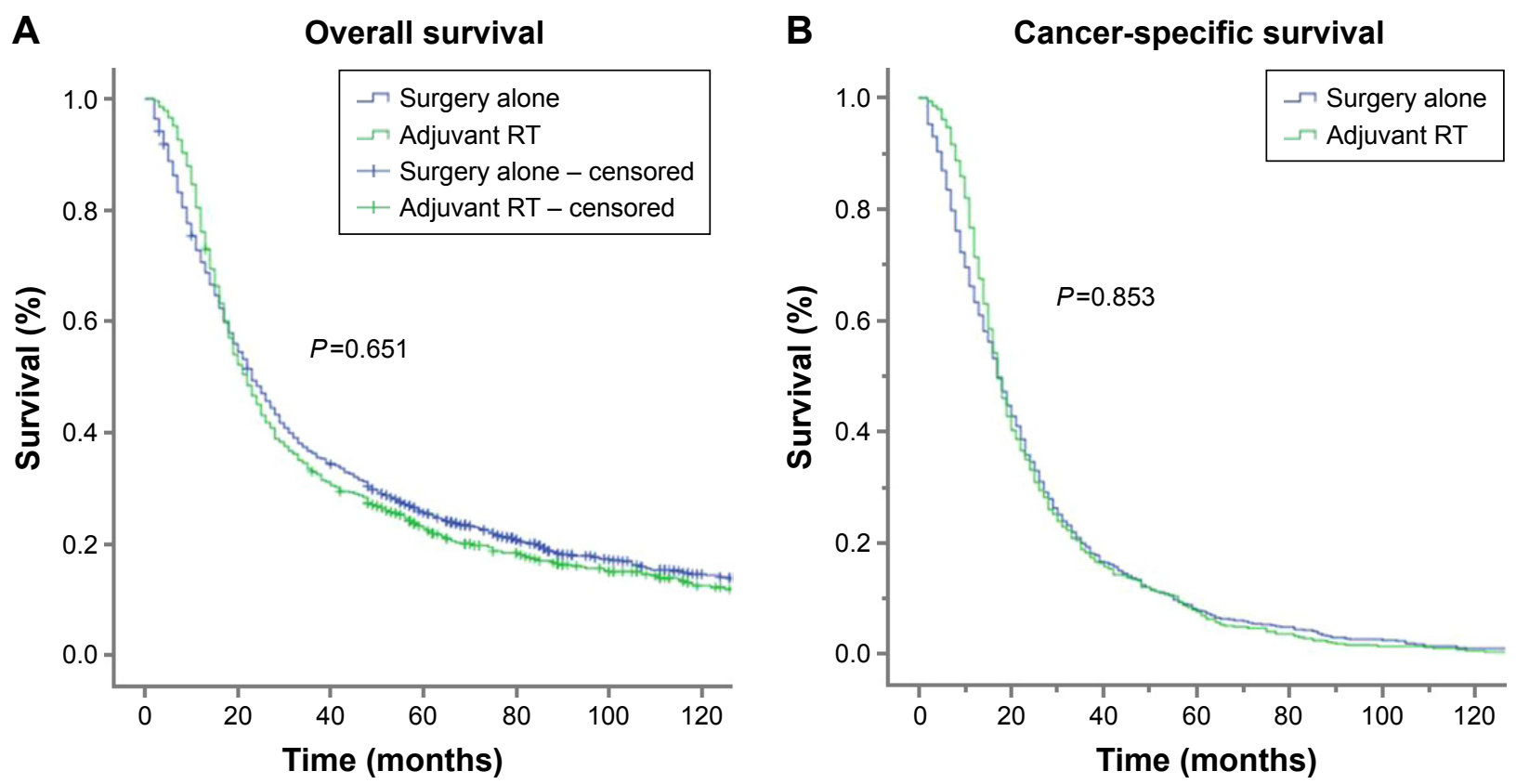

Figure 2 Kaplan-Meier analysis of $(\mathbf{A})$ overall and (B) cancer-specific survival of the adjuvant RT ( $\mathrm{n}=762$ ) and surgery alone ( $\mathrm{n}=\mathrm{I}, \mathrm{I55})$ groups before propensity score matching.

Abbreviation: $\mathrm{RT}$, radiation therapy.

of diagnosis $(P<0.001)$, tumor stage $(P<0.001)$, tumor grade $(P=0.008)$, and LN status $(P<0.001)$ were prognostic. In propensity score-matched univariate models, adjuvant RT did not improve OS $(P=0.978)$ or CSS $(P=0.554)$ when compared to surgery alone. In the multivariate Cox proportional hazard model, advanced tumor stage (vs localized

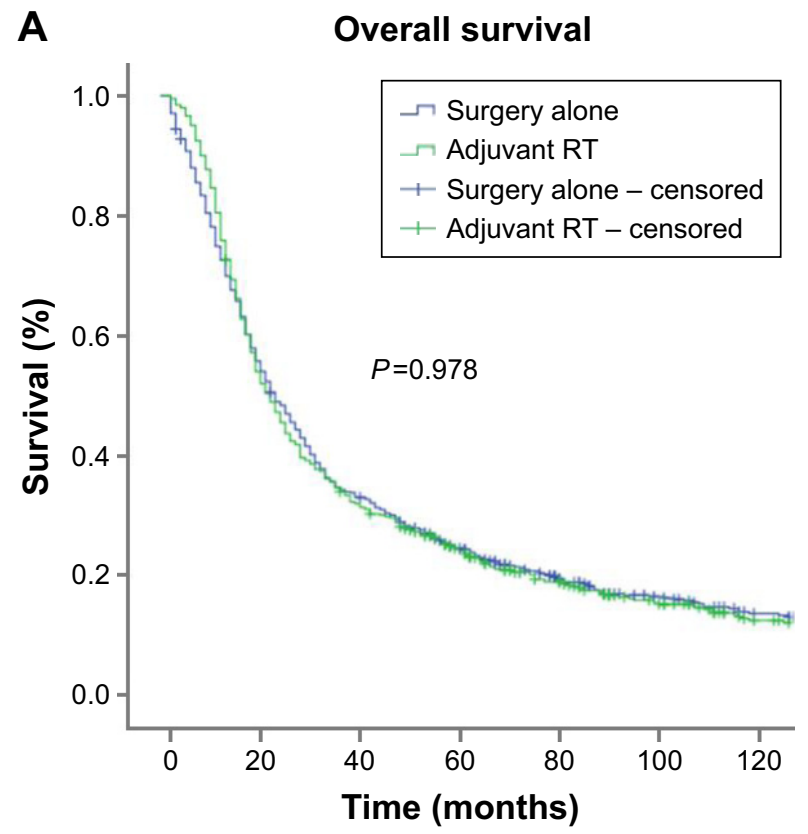

[T1-T2]; hazard ratio [HR] 1.336, 95\% confidence interval [CI] 1.085-1.621 for OS; HR 1.281, 95\% CI 1.007-1.630 for CSS), positive LN (vs negative LN; HR 1.552, 95\% CI $1.365-1.763$ for OS; HR $1.422,95 \%$ CI $1.223-1.654$ for CSS), and poor or undifferentiated grade (vs well or moderate; HR 1.164, 95\% CI 1.021-1.328 for OS; HR 1.254,

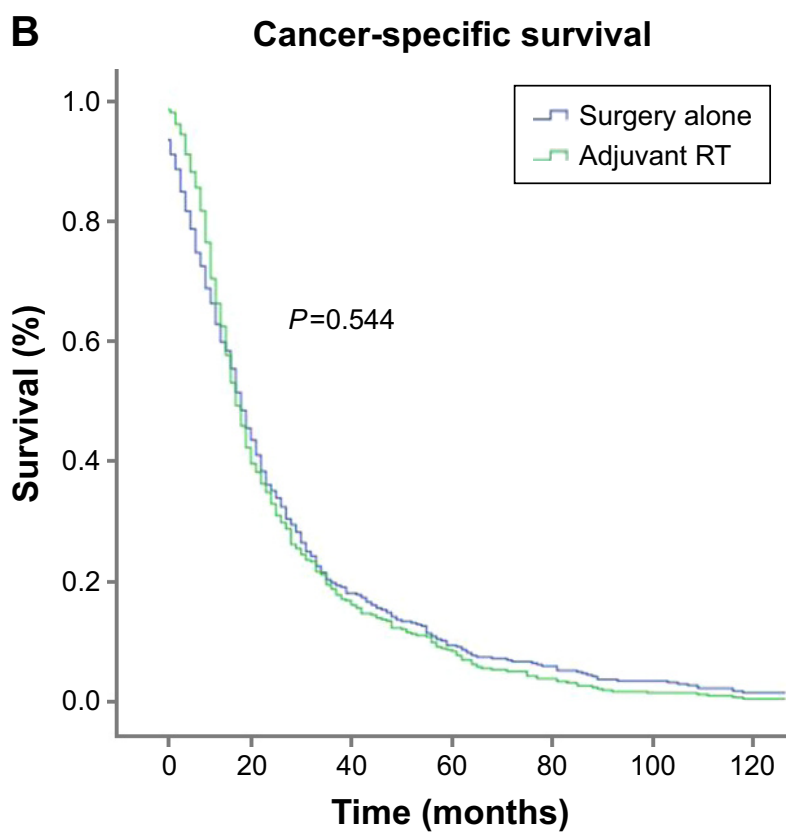

Figure 3 Kaplan-Meier analysis of $(\mathbf{A})$ overall and (B) cancer-specific survival of the adjuvant RT ( $=65 \mathrm{I}$ ) and surgery alone (n=65I) groups after propensity score matching.

Abbreviation: RT, radiation therapy. 
Table 2 Univariate analysis of the matched population for overall and cause-specific survival

\begin{tabular}{|c|c|c|c|c|}
\hline \multirow[t]{2}{*}{ Variables } & \multicolumn{2}{|l|}{ Overall survival } & \multicolumn{2}{|c|}{ Cause-specific survival } \\
\hline & Median (months) & $P$-value & Median (months) & $P$-value \\
\hline Age (years) & & $<0.001$ & & 0.178 \\
\hline$\leq 49$ & 24 & & 16 & \\
\hline $50-59$ & 25 & & 19 & \\
\hline $60-69$ & 22 & & 18 & \\
\hline $70-79$ & 21 & & 17 & \\
\hline $80+$ & 21 & & 18 & \\
\hline Gender & & & & 0.258 \\
\hline Men & 23 & 0.086 & 18 & \\
\hline Women & 19 & & 16 & \\
\hline Race & & 0.092 & & 0.888 \\
\hline White & 22 & & 17 & \\
\hline Black & 18 & & 16 & \\
\hline Others & 27 & & 19 & \\
\hline Year of diagnosis & & 0.421 & & 0.001 \\
\hline $1988-1993$ & 23 & & 19 & \\
\hline $1994-1999$ & 23 & & 19 & \\
\hline $2000-2004$ & 22 & & 18 & \\
\hline $2005-2009$ & 22 & & 17 & \\
\hline Tumor grade & & 0.005 & & 0.008 \\
\hline Well or moderate & 24 & & 19 & \\
\hline Poor or undifferentiated & 18 & & 15 & \\
\hline Unknown & 25 & & 18 & \\
\hline LN status & & $<0.001$ & & $<0.001$ \\
\hline Negative & 31 & & 21 & \\
\hline Positive & 17 & & 15 & \\
\hline Unknown & 16 & & 10 & \\
\hline Tumor size $(\mathrm{mm})$ & & $<0.001$ & & 0.057 \\
\hline$\leq 20$ & 26 & & 19 & \\
\hline$>20$ & 20 & & 17 & \\
\hline Unknown & 21 & & 17 & \\
\hline Tumor stage & & $<0.00$ I & & $<0.001$ \\
\hline Localized (TI-T2) & 37 & & 27 & \\
\hline Regional (T3-T4 and/or node positive) & 20 & & 17 & \\
\hline Unknown & 3 & & & \\
\hline Extent of surgery & & 0.851 & & 0.584 \\
\hline Radical & 22 & & 18 & \\
\hline Limited & 23 & & 18 & \\
\hline Treatment & & 0.978 & & 0.554 \\
\hline Adjuvant RT & 22 & & 17 & \\
\hline Surgery alone & 23 & & 18 & \\
\hline
\end{tabular}

Abbreviations: LN, lymph node; RT, radiation therapy.

95\% CI 1.072-1.466 for CSS) were significantly associated with poorer OS and CSS. Adjuvant RT in propensity score adjusted multivariate models also failed to improve survival (vs surgery alone; HR 1.005, 95\% CI 0.893-1.131 for OS; HR $0.971,95 \%$ CI $0.845-1.115$ for CSS) (Table 3). In order to access the role of adjuvant RT among patients with unfavorable tumor characteristics, the matched population was further stratified by poor prognostic tumor characteristics (Table S1). Among patients with regional tumor stage (21 vs 20 months, $P=0.901$ ), presence of poor or undifferentiated grade ( 18 vs 18 months, $P=0.995$ ), and positive LN
(21 vs 20 months, $P=0.689$ ), adjuvant RT was not associated with a better survival (Table S1).

\section{Discussion}

The present study found no significant survival benefit from adjuvant RT for patients with resected pCCA. Advanced tumor stage, frequent LN metastasis, and poor to undifferentiated histologic grade were tumor characteristics significantly associated with poorer OS and CSS. Patients with adverse tumor characteristics also did not have significantly superior survival with adjuvant RT as compared to those 
Table 3 Multivariate analysis of the matched population for overall and cause-specific survival

\begin{tabular}{|c|c|c|c|c|c|c|}
\hline \multirow[t]{2}{*}{ Variables } & \multicolumn{3}{|c|}{ Overall survival } & \multicolumn{3}{|c|}{ Cause-specific survival } \\
\hline & Hazard ratio & $95 \% \mathrm{Cl}$ & $P$-value & Hazard ratio & $95 \% \mathrm{Cl}$ & $P$-value \\
\hline \multicolumn{7}{|l|}{ Age (years) } \\
\hline$\leq 49$ & 0.586 & $0.428-0.803$ & 0.001 & & & \\
\hline $50-59$ & 0.655 & $0.500-0.859$ & 0.002 & & & \\
\hline $60-69$ & 0.796 & $0.617-1.028$ & 0.080 & & & \\
\hline $70-79$ & 0.913 & $0.706-1.182$ & 0.491 & & & \\
\hline $80+$ & Reference & & & & & \\
\hline \multicolumn{7}{|l|}{ Gender } \\
\hline Men & 0.957 & $0.846-1.083$ & 0.490 & & & \\
\hline Women & Reference & & & & & \\
\hline \multicolumn{7}{|l|}{ Race } \\
\hline White & 1.051 & $0.880-1.255$ & 0.580 & & & \\
\hline Black & $1.46 \mathrm{I}$ & $1.054-2.035$ & 0.023 & & & \\
\hline Others & Reference & & & & & \\
\hline \multicolumn{7}{|l|}{ Year of diagnosis } \\
\hline $1988-1993$ & & & & 0.729 & $0.570-0.931$ & 0.011 \\
\hline $1994-1999$ & & & & 0.740 & $0.605-0.905$ & 0.003 \\
\hline 2000-2004 & & & & 0.875 & $0.739-1.036$ & 0.121 \\
\hline 2005-2009 & & & & Reference & & \\
\hline \multicolumn{7}{|l|}{ Tumor grade } \\
\hline Well or moderate & Reference & & & Reference & & \\
\hline Poor or undifferentiated & 1.164 & $\mathrm{I} .021-\mathrm{I} .328$ & 0.024 & 1.254 & $1.072-1.466$ & 0.005 \\
\hline Unknown & 0.940 & $0.752-1.176$ & 0.588 & 1.072 & $0.832-1.380$ & 0.591 \\
\hline \multicolumn{7}{|l|}{ LN status } \\
\hline Negative & Reference & & & Reference & & \\
\hline Positive & 1.552 & $1.365-1.763$ & $<0.001$ & 1.422 & $1.223-1.654$ & $<0.001$ \\
\hline Unknown & 1.753 & $1.215-2.527$ & 0.003 & 3.013 & I.889-4.807 & $<0.001$ \\
\hline \multicolumn{7}{|l|}{ Tumor size (mm) } \\
\hline$\leq 20$ & Reference & & & Reference & & \\
\hline$>20$ & 1.229 & $\mathrm{I} .063-\mathrm{I} .422$ & 0.005 & 1.089 & $0.915-1.296$ & 0.337 \\
\hline Unknown & 1.439 & $1.245-1.662$ & $<0.001$ & 1.120 & $0.945-1.328$ & 0.190 \\
\hline \multicolumn{7}{|l|}{ Tumor stage } \\
\hline Localized (TI-T2) & Reference & & & Reference & & \\
\hline Regional (T3-T4 and/or node positive) & 1.326 & $1.085-1.621$ & 0.006 & 1.281 & $1.007-1.630$ & 0.044 \\
\hline Unknown & 0.868 & $0.205-3.667$ & 0.847 & & & \\
\hline \multicolumn{7}{|l|}{ Treatment } \\
\hline Adjuvant RT & 1.005 & $0.893-|| 3 \mid$. & 0.938 & 0.971 & $0.845-1.115$ & 0.674 \\
\hline Surgery alone & Reference & & & Reference & & \\
\hline
\end{tabular}

Abbreviations: $\mathrm{Cl}$, confidence interval; $\mathrm{LN}$, lymph node; RT, radiation therapy.

without high-risk features. These data suggest that adjuvant RT should not be routinely used to treat patients with pCCA outside research trials.

pCCA is an uncommon tumor with a poor prognosis. It still remains difficult to achieve negative microscopic margins, which may offer the only hope of cure and longterm survival for pCCA. It is reported that the primary site of recurrence following complete resection is usually locoregional in patients with pCCA $(59 \%) .{ }^{8}$ Thus, RT has frequently been recommended both as adjuvant therapy for resected patients and as primary treatment for unresectable patients. However, the role of locoregional therapy with adjuvant RT for pCCA remains controversial (Table S2).
To date, several studies have demonstrated that adjuvant RT was independently associated with improved survival in patients with pCCA. Todoroki et al found an increase in 5-year survival from $13 \%$ to $34 \%$ among patients receiving adjuvant RT. ${ }^{13}$ One study in China reported a $10 \%$ increase in the 5-year survival among patients who received adjuvant $\mathrm{RT}$, indicating that adjuvant external beam radiation was independently associated with better outcomes. ${ }^{14}$ Another study from the Netherlands found that those who did not receive adjuvant RT had a median survival of 8 versus 24 months for patients who did undergo adjuvant RT. ${ }^{15}$ In contrast, Sagawa et al reported their study including 69 patients undergoing surgical resection for pCCA; however, 
no survival benefit at 3 years was detected among patients with pCCA who received adjuvant RT. ${ }^{12}$ Pitt et al also found that adjuvant RT had no effect on OS. ${ }^{10}$ The interpretation of these reports is difficult because of a mixture of R0 and R1 resections and very small patient groups. In addition, it is found that patients with adverse tumor characteristics were more likely to receive adjuvant RT, which would result in cautious interpretation of the results.

This study found that $39.7 \%$ of patients received adjuvant RT after curative intent resection. As expected, receipt of adjuvant RT was not random but instead was related to specific clinical and pathological factors. Patients who underwent adjuvant RT had more adverse characteristics compared with patients who underwent surgery alone. In particular, it was found that factors including younger patient age, LN metastasis, and advanced tumor stage were all associated with a higher likelihood of receiving adjuvant RT. As such, it was clearly demonstrated that patients who received adjuvant $\mathrm{RT}$ were not comparable to patients who received surgery alone with regard to underlying tumor biology. Therefore, it is not surprising that with nonpropensity-matched analyses, patients receiving adjuvant RT had worse 5-year OS. The present study is important because it used propensity score matching to more fully control for baseline differences in the two groups. Using propensity score matching, two groups of patients with similar baseline characteristics were identified, which ultimately made the present analysis much more effective. In the univariate analysis, adjuvant RT failed to improve either OS or CSS in matched pCCA patients after surgical resection. Accordingly, the efficacy of adjuvant RT in local tumor control was questionable. Although multiple high-risk tumor characteristics were controlled, multivariate analysis in the matched population was also unable to establish a survival benefit from adjuvant RT. Taken together, the data suggested that adjuvant RT had no effect on survival of patients with resected pCCA.

There are several potential interfering factors that affect the results of this study to some degree. The first issue to be addressed is whether the dose of radiation was adequate. It is technically challenging to make rational and efficacious radiotherapy protocols for pCCA. Until now, no consensus has been established. Gonzalez Gonzalez et al suggested a dose $>70$ Gy because of the concept that CCA is a radioresistant tumor. ${ }^{22}$ However, if radiation treatment with much higher dose caused serious toxicity that aborted treatment before completion, the patients would not benefit from adjuvant RT. Information regarding radiotherapy dose, radiotherapy plans, or whether radiotherapy courses were completed after initiation of therapy were not obtained. A second issue that may have inhibited the influence of radiation was whether radiation was given alone without concomitant sensitizing chemotherapy or not. The question of adjuvant chemotherapy still remains vague in pCCA. There are only few data for adjuvant chemotherapy in patients with CCA following curative intent surgery. ${ }^{23}$ In general, there is no clear evidence for an OS benefit of adjuvant chemotherapy for not selected patients. ${ }^{24}$ Finally, resection margin may have influenced survival outcomes. However, several studies reported that the effect of margin status on survival among patients with resected pCCA who received adjuvant chemoradiation therapy is minimal. ${ }^{22,25}$ The SEER database lacks its ability to capture margin status and chemotherapy regimens, but it seems to have little impact on this study. In addition, this study is the first large population-based study to investigate the role of adjuvant RT in pCCA. The potential selection bias in patients receiving adjuvant RT could be minimized by using propensity score matching. Although randomized evidence regarding adjuvant RT in resected pCCAs was absent, the result from this propensity score-matched analysis can provide insight into optimal treatment after curative intent surgery.

There are some other limitations to the current study. Although it is supposed that patients underwent surgical resection with curative intent, this important concept is still difficult to fully evaluate due to the lack of information regarding surgical details and margin status. The present study is also limited by the inability to obtain information regarding disease recurrence. Therefore, it is difficult to assess whether adjuvant RT is associated with better diseasefree survival and/or lower rates of local recurrence. Even though the SEER database is large, pCCA is an uncommon cancer and only $39.7 \%$ of patients underwent adjuvant RT. Hence, the size of this study cohort limited the ability to detect significant associations between adjuvant RT and clinical outcomes. The last limitation of this study is that propensity score match did not include performance status, which is highly prognostic.

\section{Conclusion}

$\mathrm{RT}$ is not associated with improved survival of patients with resected pCCA. The present study is considered important because the SEER database shows that a large proportion of patients with resected pCCA are currently being treated with adjuvant RT despite the lack of definitive evidence from randomized trials. Ideally, prospective randomized trials should be performed to verify the conclusion of this study. 


\section{Acknowledgments}

This work was supported by the National Natural Science Foundation of China (Grant No 81602088), Health and Family Planning Commission Research Project of Heilongjiang Province (Grant No 2016-049), Innovative Science Foundation of Harbin Medical University (Grant No 2016LCZX09), and Natural Science Foundation of Heilongjiang Province (Grant No H201396).

\section{Disclosure}

The authors report no conflicts of interest in this work.

\section{References}

1. Siegel R, Naishadham D, Jemal A. Cancer statistics, 2013. CA Cancer J Clin. 2013;63(1):11-30.

2. Blechacz B, Komuta M, Roskams T, Gores GJ. Clinical diagnosis and staging of cholangiocarcinoma. Nat Rev Gastroenterol Hepatol. 2011;8(9):512-522.

3. Cardinale V, Semeraro R, Torrice A, et al. Intrahepatic and extrahepatic cholangiocarcinoma: new insight into epidemiology and risk factors. World J Gastrointest Oncol. 2010;2(11):407-416.

4. Kobayashi A, Miwa S, Nakata T, Miyagawa S. Disease recurrence patterns after R0 resection of hilar cholangiocarcinoma. Br J Surg. 2010; 97(1):56-64

5. Lee SG, Song GW, Hwang S, et al. Surgical treatment of hilar cholangiocarcinoma in the new era: the Asan experience. $J$ Hepatobiliary Pancreat Sci. 2010;17(4):476-489.

6. van Gulik TM, Kloek JJ, Ruys AT, et al. Multidisciplinary management of hilar cholangiocarcinoma (Klatskin tumor): extended resection is associated with improved survival. Eur J Surg Oncol. 2011;37(1): $65-71$.

7. Ito F, Agni R, Rettammel RJ, et al. Resection of hilar cholangiocarcinoma: concomitant liver resection decreases hepatic recurrence. Ann Surg. 2008;248(2):273-279.

8. Jarnagin WR, Ruo L, Little SA, et al. Patterns of initial disease recurrence after resection of gallbladder carcinoma and hilar cholangiocarcinoma: implications for adjuvant therapeutic strategies. Cancer. 2003; 98(8):1689-1700.

9. Cameron JL, Pitt HA, Zinner MJ, Kaufman SL, Coleman J. Management of proximal cholangiocarcinomas by surgical resection and radiotherapy. Am J Surg. 1990;159(1):91-97.

10. Pitt HA, Nakeeb A, Abrams RA, et al. Perihilar cholangiocarcinoma. Postoperative radiotherapy does not improve survival. Ann Surg. 1995; 221(6):788-797.
11. Zlotecki RA, Jung LA, Vauthey JN, Vogel SB, Mendelhall WM. Carcinoma of the extrahepatic biliary tract: surgery and radiotherapy for curative and palliative intent. Radiat Oncol Investig. 1998;6(5):240-247.

12. Sagawa N, Kondo S, Morikawa T, Okushiba S, Katoh H. Effectiveness of radiation therapy after surgery for hilar cholangiocarcinoma. Surg Today. 2005;35(7):548-552.

13. Todoroki T, Ohara K, Kawamoto T, et al. Benefits of adjuvant radiotherapy after radical resection of locally advanced main hepatic duct carcinoma. Int J Radiat Oncol Biol Phys. 2000;46(3):581-587.

14. Cheng Q, Luo X, Zhang B, Jiang X, Yi B, Wu M. Predictive factors for prognosis of hilar cholangiocarcinoma: postresection radiotherapy improves survival. Eur J Surg Oncol. 2007;33(2):202-207.

15. Gerhards MF, van Gulik TM, González González D, Rauws EA, Gouma DJ. Results of postoperative radiotherapy for resectable hilar cholangiocarcinoma. World J Surg. 2003;27(2):173-179.

16. Mahadevan A, Dagoglu N, Mancias J, et al. Stereotactic body radiotherapy (SBRT) for intrahepatic and hilar cholangiocarcinoma. $J$ Cancer. 2015;6(11):1099-1104.

17. González González D, Gerard JP, Maners AW, et al. Results of radiation therapy in carcinoma of the proximal bile duct (Klatskin tumor) Semin Liver Dis. 1990;10(2):131-141.

18. Warren JL, Klabunde CN, Schrag D, Bach PB, Riley GF. Overview of the SEER-Medicare data: content, research applications, and generalizability to the United States elderly population. Med Care. 2002; 40(8 Suppl):13-18.

19. Zippin C, Lum D, Hankey BF. Completeness of hospital cancer case reporting from the SEER Program of the National Cancer Institute. Cancer. 1995;76(11):2343-2350.

20. Rosenbaum PR, Rubin DB. The central role of the propensity score in observational studies for causal effects. Biometrika. 1983;70:41-55.

21. Rosenbaum PR, Rubin DB. Constructing a control group using multivariate matched sampling methods that incorporate the propensity score. Am Stat. 1985;39(5):33-38.

22. González González D, Gouma DJ, Rauws EA, van Gulik TM, Bosma A, Koedooder C. Role of radiotherapy, in particular intraluminal brachytherapy, in the treatment of proximal bile duct carcinoma. Ann Oncol. 1999;10(4 Suppl):215-220.

23. Murakami Y, Uemura K, Sudo T, et al. Gemcitabine-based adjuvant chemo-therapy improves survival after aggressive surgery for hilar cholangiocarcinoma. J Gastrointest Surg. 2009;13(3):1470-1479.

24. Brunner TB, Seufferlein T. Radiation therapy in cholangiocellular carcinomas. Best Pract Res Clin Gastroenterol. 2016;30(4): 593-602.

25. Borghero Y, Crane CH, Szklaruk J, et al. Extrahepatic bile duct adenocarcinoma: patients at high risk for local recurrence treated with surgery and adjuvant chemoradiation have an equivalent overall survival to patients with standard-risk treated with surgery alone. Ann Surg Oncol. 2008;15(11):3147-3156. 


\section{Supplementary materials}

Table SI Survival analysis in the propensity score-matched treatment cohorts for patients with high-risk tumor characteristics

\begin{tabular}{|c|c|c|c|c|}
\hline \multirow[t]{2}{*}{ Variables } & \multicolumn{2}{|l|}{ Overall survival } & \multicolumn{2}{|c|}{ Cancer-specific survival } \\
\hline & Median (months) & $P$-value & Median (months) & $P$-value \\
\hline Regional tumor stages (T3-T4 and/or node positive) & & 0.901 & & 0.494 \\
\hline Surgery alone & 21 & & 17 & \\
\hline Adjuvant RT & 20 & & 17 & \\
\hline Positive LN & & 0.689 & & 0.851 \\
\hline Surgery alone & 17 & & 15 & \\
\hline Adjuvant RT & 17 & & 16 & \\
\hline Poor or undifferentiated grade & & 0.995 & & 0.843 \\
\hline Surgery alone & 18 & & 15 & \\
\hline Adjuvant RT & 18 & & 15 & \\
\hline
\end{tabular}

Abbreviations: LN, lymph node; RT, radiation therapy.

Table S2 Published survival outcomes with or without adjuvant RT for resected pCCA

\begin{tabular}{|c|c|c|c|c|c|c|c|}
\hline \multirow[t]{2}{*}{ Series } & \multirow[t]{2}{*}{ Year } & \multirow[t]{2}{*}{$\mathbf{N}$} & \multicolumn{2}{|l|}{ OS (\%) } & \multicolumn{2}{|c|}{ Median survival (months) } & \multirow{2}{*}{$\begin{array}{l}\text { Survival benefit } \\
\text { from adjuvant RT }\end{array}$} \\
\hline & & & Surgery alone & Adjuvant RT & Surgery alone & Adjuvant RT & \\
\hline \multirow[t]{2}{*}{ Cameron et al' } & 1990 & 53 & 3 years OS: 21 & 3 years OS: 21 & NS & NS & Yes \\
\hline & & & 5 years OS: 0 & 5 years OS: II & & & \\
\hline González González et al ${ }^{2}$ & 1990 & 55 & 3 years OS: 10 & 3 years OS: 31 & 8 & 19 & Yes \\
\hline Pitt et $\mathrm{al}^{3}$ & 1995 & 50 & NS & NS & 15 & 14 & No \\
\hline Todoroki et $\mathrm{al}^{4}$ & 2000 & 63 & 5 years OS: 13.4 & 5 years OS: 39.2 & 10 & 36 & Yes \\
\hline Gerhards et $\mathrm{al}^{5}$ & 2003 & 84 & 5 years OS: II & 5 years OS: 19 & 8 & NS & Yes \\
\hline Sagawa et al ${ }^{6}$ & 2005 & 69 & 3 years OS: 33.3 & 3 years OS: 40.9 & NS & NS & No \\
\hline Cheng et $\mathrm{al}^{7}$ & 2007 & 75 & NS & NS & NS & NS & Yes \\
\hline
\end{tabular}

Abbreviations: N, number of patients; NS, not specified; OS, overall survival; pCCA, perihilar cholangiocarcinoma; RT, radiation therapy.

\section{References}

1. Cameron JL, Pitt HA, Zinner MJ, Kaufman SL, Coleman J. Management of proximal cholangiocarcinomas by surgical resection and radiotherapy. Am J Surg. 1990;159(1):91-97.

2. González González D, Gerard JP, Maners AW, et al. Results of radiation therapy in carcinoma of the proximal bile duct (Klatskin tumor). Semin Liver Dis. 1990;10(2):131-141.

3. Pitt HA, Nakeeb A, Abrams RA, et al. Perihilar cholangiocarcinoma. Postoperative radiotherapy does not improve survival. Ann Surg. 1995; 221(6):788-797.

4. Todoroki T, Ohara K, Kawamoto T, et al. Benefits of adjuvant radiotherapy after radical resection of locally advanced main hepatic duct carcinoma. Int J Radiat Oncol Biol Phys. 2000;46(3):581-587.
5. Gerhards MF, van Gulik TM, González González D, Rauws EA, Gouma DJ. Results of postoperative radiotherapy for resectable hilar cholangiocarcinoma. World J Surg. 2003;27(2):173-179.

6. Sagawa N, Kondo S, Morikawa T, Okushiba S, Katoh H. Effectiveness of radiation therapy after surgery for hilar cholangiocarcinoma. Surg Today. 2005;35(7):548-552.

7. Cheng Q, Luo X, Zhang B, Jiang X, Yi B, Wu M. Predictive factors for prognosis of hilar cholangiocarcinoma: postresection radiotherapy improves survival. Eur J Surg Oncol. 2007;33(2):202-207.
OncoTargets and Therapy

\section{Publish your work in this journal}

OncoTargets and Therapy is an international, peer-reviewed, open access journal focusing on the pathological basis of all cancers, potential targets for therapy and treatment protocols employed to improve the management of cancer patients. The journal also focuses on the impact of management programs and new therapeutic agents and protocols on

\section{Dovepress}

patient perspectives such as quality of life, adherence and satisfaction. The manuscript management system is completely online and includes a very quick and fair peer-review system, which is all easy to use. Visit http://www.dovepress.com/testimonials.php to read real quotes from published authors. 